\title{
Field Testing and Analysis of Embankment Vibrations Induced by Heavy Haul Trains
}

\author{
Peng Li, ${ }^{1,2,3}$ Xianzhang Ling, ${ }^{1,2,3}$ Feng Zhang, ${ }^{4}$ Yan $\mathrm{Li}^{1,2,3}$ and Yingying Zhao ${ }^{1,2,3}$ \\ ${ }^{1}$ School of Civil Engineering, Harbin Institute of Technology, Harbin 150090, China \\ ${ }^{2}$ Key Laboratory of Structures Dynamic Behavior and Control of the Ministry of Education, Harbin Institute of Technology, Harbin \\ 150090, China \\ ${ }^{3}$ Key Laboratory of Smart Prevention and Mitigation of Civil Engineering Disasters of the Ministry of Industry and Information \\ Technology, Harbin Institute of Technology, Harbin 150090, China \\ ${ }^{4}$ School of Transportation Science and Engineering, Harbin Institute of Technology, Harbin 150090, China \\ Correspondence should be addressed to Peng Li; hit_lp@163.com
}

Received 9 February 2017; Accepted 16 April 2017; Published 10 May 2017

Academic Editor: Georges Kouroussis

Copyright (c) 2017 Peng Li et al. This is an open access article distributed under the Creative Commons Attribution License, which permits unrestricted use, distribution, and reproduction in any medium, provided the original work is properly cited.

\begin{abstract}
This paper presents a field testing of track and ground-borne vibration generated by heavy haul trains. The test sites consisted of three embankments with height of 6.6, 8.1, and 11.9, respectively. The acceleration signals of the rail, sleeper, and embankment surface were recorded, and then the propagation characteristics of ground vibration with distance to track center were contrastively analyzed. The test results show that horizontal vibration was dominant for locations near the track but decreased rapidly and became comparable with the vertical levels as the distance from track center increases. The quasi-static excitation dominated the sleeper response, and the dominant frequency range was found in the low-frequency zone corresponding to the fundamental axle passage frequency. For embankment surface, another pronounced dominant frequency zone was observed between 30 and $80 \mathrm{~Hz}$, which was attributed to the dynamic excitation. Moreover, these higher frequency components were more promptly attenuated than lowfrequency ones. The reason that vibration levels generated by locomotive were greater than wagon was attributed to the different bogie suspension mode. The relationship between normalized PPV and distance from track center in doubly logarithmic scales can be expressed with exponential function, and the vibration attenuation rates were restrained with increasing the embankment height.
\end{abstract}

\section{Introduction}

With the rapid increase of train speed, loading capacity, and wagon axle load, the problem of train-induced ground vibrations has recently received considerable attentions for both passenger and freight transportation services. This increased interest is not only due to the severe disturbance to person and buildings in the vicinity of the railway lines, but also due to the fatigue effects on the track and the significant deterioration of the adjacent subgrade structures [1].

Over the years, since it is impractical to carry out field measurement under some certain conditions, many numerical models have been proposed in time domain and frequency domain to predict the vibration behavior of railway lines, taking into account the factors related to local soil properties and train-track-subgrade interaction effects [2-6]. Moreover, Paolucci et al. [7] assumed that in the low-frequency range the dynamic interaction between train and track can be disregarded and employed a series of moving static forces to simulate the train loading below $50 \mathrm{~Hz}$. In greater detail, Lombaert and Degrande [8] attributed the excitations of train-induced vibration to quasi-static and dynamic and proposed a numerical model to simulate the vibrations under random track unevenness. His results showed that, in the subcritical speed, the quasi-static excitation dominated the track response, while the free-field response was dominated by the dynamic contribution. Another method was proposed by Connolly et al. [9] who used a time domain threedimensional finite element model considering the nonlinear excitation mechanisms, and the results showed that stiff 
embankments reduced vibrations in the near and far fields in comparison to soft ones. We can see that more cases with various variable parameters can be considered through numerical methods, but there are also some assumptions that must be made about the boundary conditions and soil properties distribution. In addition, limited to the computer hardware level, it is difficult to simulate some high frequency contents of track and free-field vibrations for the used time increment during computation.

In order to overcome some of the limitations associated with numerical analysis methods, researchers have performed lots of in situ experiments on various railway sites to obtain the practical vibration propagation characteristics [10-16]. As well known, a moving train radiates vibrations as both body and surface waves in various directions, of which the Rayleigh surface wave carries most of the energy due to different geometric attenuation [17]. For the tracks on soft soil, Madshus et al. [18] had experimentally observed that as a train traveled faster than the Rayleigh wave speed in the ground, very large increase in ground vibration amplitudes was aroused, which severely exacerbated the running conditions. Although this phenomenon was not yet common in majority of the practical running cases, the rapid extension of high speed railway all over the world still initiated a lot of investigations mainly on the influence of train speed on the vibration characteristics. For instance, another detailed research around the effect of critical speed was carried out by Auersch [19], who pointed out that the amplification effect of critical speed can be reduced by increasing the load frequency or track width based on numerical results obtained in frequency wavenumber domain, and his theoretical results were verified by the field measurements on a soft and stiff site, respectively. Connolly et al. [20-22] compared the vibration levels and attenuation rules according to the measurements results from different earthwork profiles, containing at-grade, embankment, cutting, and overpass, but unfortunately low dependency of vibration levels upon the train speed was observed. Moreover, contrary to commonly accepted phenomenon, the horizontal vibrations were the most dominant in some test cases. In addition, Alves Ribeiro et al. [23] and Varandas et al. [24] also took experimental research on the effects of culvert on track vibration. So far, a large number of field tests have been carried out for high speed railway with axle load up to 17 tons and running speed up to $425 \mathrm{~km} / \mathrm{h}$, covering most of the train types as Eurostar, TGV, and CRH.

On the other hand, compared to high speed railway, it should be noted that freight transportation requires considerably heavier trains to enhance the loading capacity. The increase of static axle load is likely to result in some accelerated damage of track components, such as degradation of ballast and cracking of sleepers [25]. It is therefore of particular importance to be able to assess the probable levels of expected track damage for both new-built and upgraded lines. In the early studies, many investigations were carried out to inspect the viability of running ten thousand tons train on Datong-Qinhuangdao heavy haul railway, the annual volume of which had exceeded 4 hundred million tons by 2010. Cai and Huang [26] measured the dynamic responses of the track and subgrade structures, and the recorded results indicated that wagons induced larger vibration levels than locomotives, while the combined train generated nearly three times of vibration levels than that from unit train. In other words, the increase of the loading period partly aggravated the vibrations of track structure. But it was necessary to note that in the initial stage the static axle load of the test wagon $\mathrm{C}_{62}$ was only 21 tons. As the axle load of coal wagon had been increased to 25 tons recently, Xiao and Lei [27] focused their research on the variation of dynamic stress in subgrade on the same railway line and observed that the coal wagon $\mathrm{C}_{80}$ induced greater loads than locomotives, but the increase of dynamic stress with the loading capacity was not obvious. For this situation, the most possible reason was that the track and subgrade conditions had been reinforced in the past decade. To the dynamic responses of bridge-embankment transition zone, Shi et al. [28] and Liu et al. [29] carried out extensive field measurements on Shuozhou-Huanghua heavy haul railway line and proposed 3D finite element methods for predicting vibrations under larger axle load conditions. It was found that the vibration behaviors of transition zone were more likely to be influenced by axle load than train speed, especially when the axle load exceeds 22 tons.

A review of the available literatures about train-induced vibrations shows that investigations relating to freight trains are relatively scarce, especially to the heavy haul railway lines under various locomotives and wagons formations with the axle load equal to or greater than 25 tons. In addition, much more attentions have been paid to the vertical dynamic responses of ground for the purpose of controlling the differential settlement in subgrade, resulting in the dynamic behavior of railway tracks in the horizontal direction not being analyzed that much and requiring deeper investigation.

This paper presents an in situ experiment which was carried out on three embankments with increasing height. The main objective is to get a comprehensive knowledge about the vibration characteristics of embankment due to the passage of heavy haul trains, as well as the corresponding propagation rules along the ground surface in the horizontal direction. The resulting values are not intended to be absolute indicators of the vibration amplitudes but can be used in a comparative way to assess the influences of train type and running speed. In addition, the recorded results are also expected to provide guidance for improving the existing numerical prediction models. The outline of the present paper is as follows. First, the detailed measuring scheme is presented, including the used instruments, site conditions, and arrangement of measuring points. Second, the variation of peak particle velocities of the rail, sleeper, and embankment surface with distances to the track center in time domain are analyzed. Then, based on the recorded time domain signals, frequency characteristics of the train-induced vibration are presented in Section 3.2. Finally, the factors affecting embankment vibration and vibration attenuation rules are summarized.

\section{Measurement Details}

In October 2014, field measurements were carried out at Baotou City on three different embankment sections with 


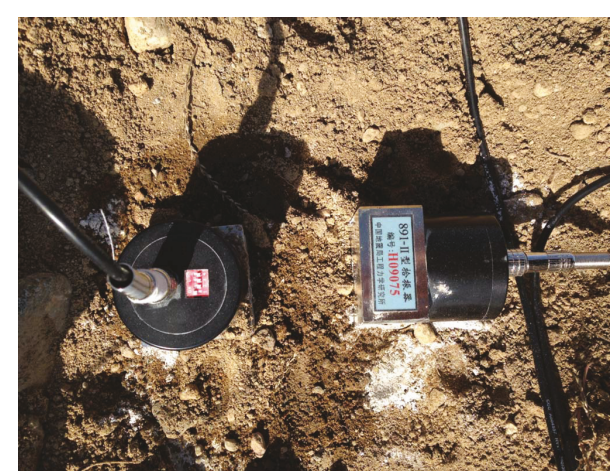

(a)

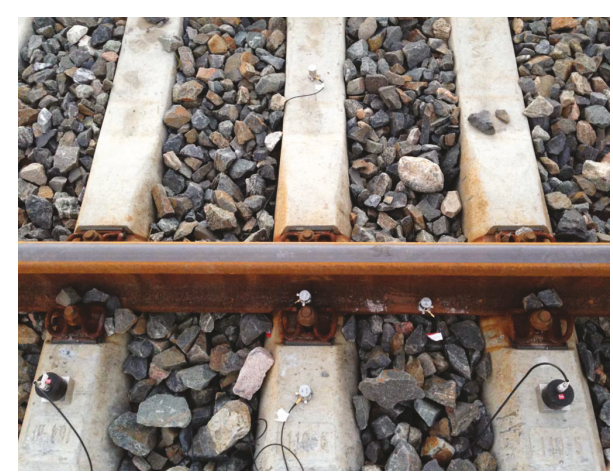

(b)

FIgURE 1: Types of accelerometers used in the test: (a) 891-2 and (b) BZ1191.

height of $6.6,8.1$, and $11.9 \mathrm{~m}$, respectively. Previous available investigations had found that the train-induced vibrations were dominant in vertical and horizontal directions $[20,30]$; thus in these tests the vibrations in longitudinal direction were not considered. Moreover, it was necessary to mention that in this paper the term track was used only to denote the superstructure including rail, sleeper, ballast, and subballast, and the ground between the subballast layer and the natural foundation was called subgrade.

2.1. Vibration Test Instruments. The vibrations of sleeper and embankment surface were measured with 891-2 accelerometers (Figure 1(a)), which were designed and produced by the Institute of Engineering Mechanics, China Earthquake Administration, with a sensitivity of $100 \mathrm{mV} / \mathrm{m} / \mathrm{s}^{2}$ and maximum acceleration measure range of $40 \mathrm{~m} / \mathrm{s}^{2}$. During the test, accelerometers were vertically anchored to the flat ground. For the measuring points on rail, due to the higher vibration frequency contents compared to the ground surface, BZ1191 piezoelectric accelerometers were selected to measure the vertical acceleration response, with a sensitivity of $5 \mu \mathrm{A} / \mathrm{m} / \mathrm{s}^{2}$. Moreover, in order to supply excitation power for BZ1191, signal conditioner LC02 was also used together. The vibration signal acquisition instrument and analysis system, DH5922, was produced by Donghua Testing Technology Co., Ltd., in Jiangsu province of China. Two sets of eight-channel DH5922 were used to simultaneously record the accelerations from horizontal direction and vertical direction. To all the accelerometers, the sampling frequency was set to $1000 \mathrm{~Hz}$.

\subsection{Description of the Test Sites}

2.2.1. Site 1 Ganqimaodu-Wanshuiquan Railway. Site 1 was located on the Ganqimaodu-Wanshuiquan heavy haul railway line (Figure 2), $33.8 \mathrm{~km}$ northwest from the initial station of Wanshuiquan. In this test section, the line was unidirectional servicing mainly for coal trains with axle load up to 25 tons. Standard CHN75 rails were used with a mass per unit length of $74.4 \mathrm{~kg}$ and moment of inertia of $4.49 \times$ $10^{-5} \mathrm{~m}^{4}$ (for single rail). IIIa prestressed concrete sleepers

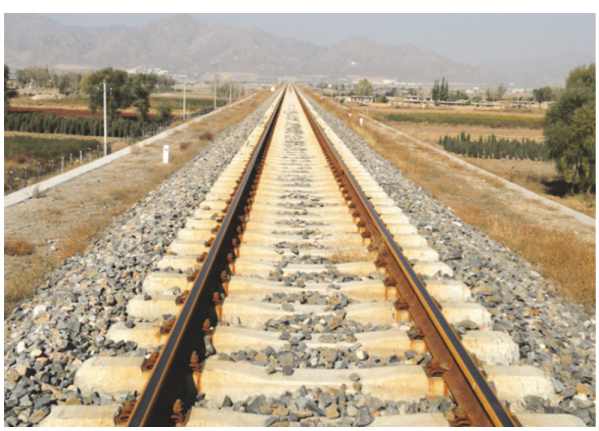

Figure 2: Test section on Ganqimaodu-Wanshuiquan heavy haul railway.

were fixed to the rails with a center to center spacing of $0.6 \mathrm{~m}$ (1680 sleepers per $\mathrm{km}$ ) and dimensions of $2.6 \mathrm{~m} \times$ $0.29 \mathrm{~m} \times 0.23 \mathrm{~m}$ (length $\times$ width $\times$ height). Between rail and sleeper, $10 \mathrm{~mm}$ thick rubber rail pads were used to absorb the vibration energy. The ballast and subballast layer formed the railway track bed with overall thickness of $0.45 \mathrm{~m}$ and top surface width of $3.4 \mathrm{~m}$.

According to the code for design on subgrade of railway (TB10001-2005), the soil profile of test section subgrade, which was an embankment with height of $6.6 \mathrm{~m}$ and slope ratio of $1: 1.5$, consisted of three components in the depth direction: formation of top layer of dense coarse graded gravel soil (thickness of $0.6 \mathrm{~m}$ ), resting on the formation base layer of sand with certain gravel content (thickness of $1.9 \mathrm{~m}$ ), and, below that, a layer of improved soil (thickness of $4.1 \mathrm{~m}$ ). For the heavy haul railway, the compacting factors of these three layers required no less than 0.95 . To verify the antiimpact ability of this test site, the distribution of the dynamic deformation modulus $E_{\mathrm{vd}}$ along the longitudinal direction of embankment top surface was measured with a portable falling weight deflectometer, and the results are shown in Figure 3. As can be seen, $E_{\mathrm{vd}}$ was unevenly distributed along the track direction due to the material difference and construction procedure, and the test section was located in a region with relatively less fluctuation and mean value of 19.23 MPa. 
TABLE 1: Formations of locomotive and wagon.

\begin{tabular}{|c|c|c|c|c|c|c|c|c|}
\hline \multirow{2}{*}{ Site } & \multirow{2}{*}{ Train number } & \multirow{2}{*}{ Speed } & \multicolumn{3}{|c|}{ Locomotive } & \multicolumn{3}{|c|}{ Wagon } \\
\hline & & & Type & Axle load & Axle number & Type & Axle load & Axle number \\
\hline Site 1 & T11 & $61 \mathrm{~km} / \mathrm{h}$ & $\mathrm{DF}_{4 \mathrm{~B}}+\mathrm{DF}_{4 \mathrm{~B}}$ & $23 \mathrm{t}$ & $6+6$ & $\mathrm{C}_{80 \mathrm{~B}}$ & $25 \mathrm{t}$ & $4 \times 54$ \\
\hline Site 2 & $\mathrm{~T} 21$ & $24 \mathrm{~km} / \mathrm{h}$ & $\mathrm{DF}_{4 \mathrm{~B}}+\mathrm{DF}_{4 \mathrm{~B}}$ & $23 \mathrm{t}$ & $6+6$ & $\mathrm{C}_{80 \mathrm{~B}}$ & $25 \mathrm{t}$ & $4 \times 57$ \\
\hline \multirow{4}{*}{ Site 3} & $\mathrm{~T} 31$ & $26 \mathrm{~km} / \mathrm{h}$ & $\mathrm{SS}_{4 \mathrm{~B}}$ & $23 \mathrm{t}$ & 8 & $\mathrm{G}_{70 \mathrm{~K}}$ & $23 \mathrm{t}$ & $4 \times 48$ \\
\hline & $\mathrm{T} 32$ & $28 \mathrm{~km} / \mathrm{h}$ & $\mathrm{SS}_{4 \mathrm{~B}}$ & $23 \mathrm{t}$ & 8 & $\mathrm{C}_{80 \mathrm{~B}}$ & $25 \mathrm{t}$ & $4 \times 51$ \\
\hline & $\mathrm{T} 33$ & $60 \mathrm{~km} / \mathrm{h}$ & $\mathrm{SS}_{4 \mathrm{~B}}+\mathrm{DF}_{4 \mathrm{~B}}$ & $23 \mathrm{t}$ & $8+6$ & $\mathrm{KZ}_{70}$ & $23 \mathrm{t}$ & $4 \times 22$ \\
\hline & T34 & $23 \mathrm{~km} / \mathrm{h}$ & $\mathrm{SS}_{4 \mathrm{~B}}$ & $23 \mathrm{t}$ & 8 & $\mathrm{C}_{70 \mathrm{E}}$ & $23 \mathrm{t}$ & $4 \times 53$ \\
\hline
\end{tabular}

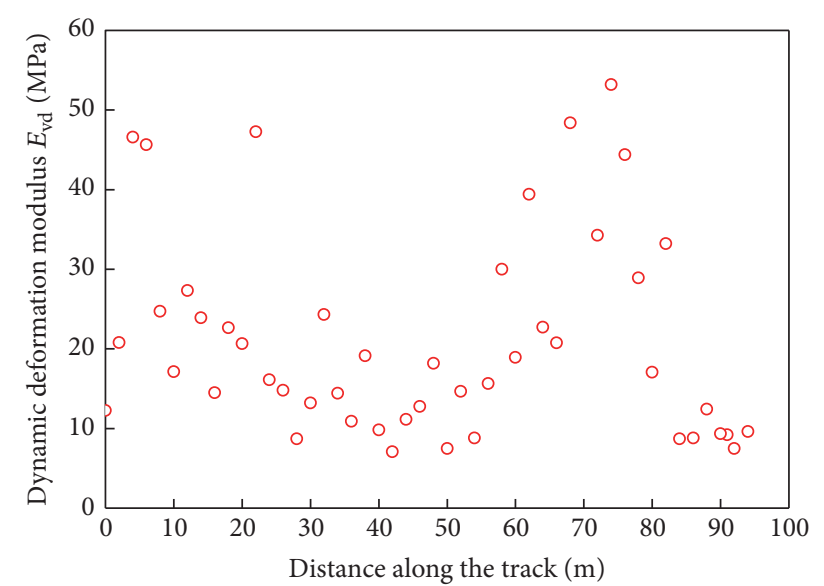

FIGURE 3: Distribution of dynamic deformation modulus along the track longitudinal direction for site 1 .

In order to analyze the propagation and attenuation regularities of train-induced vibration, the acceleration responses of 9 locations along the track and embankment surface were recorded during the train passage (Figure 4(a)). For the subgrade vibration, five measuring points were arranged from foundation surface to embankment top surface marked as $\mathrm{C} 11, \mathrm{C12}$, C13, C14, and C15, respectively. At each position, two accelerometers were placed perpendicularly to measure the vibration in the horizontal and vertical direction simultaneously. Considering the track components vibration, positions $\mathrm{C} 16, \mathrm{C} 18$, and $\mathrm{C} 19$ were fixed on the sleepers, and $\mathrm{C} 17$ was set on the rail profile. For these four points, only vertical accelerations were recorded.

2.2.2. Site 2 Tarangaole-Hanjiacun Railway. Site 2 was located on the Tarangaole-Hanjiacun heavy haul railway line, approximately $10 \mathrm{~km}$ north from the Dongsheng station. The test section configuration and accelerometers arrangement were shown in Figure 4(b). As the height of this embankment has reached $11.9 \mathrm{~m}$, two slope gradient levels were adopted, $1: 1.75$ and $1: 1.5$, respectively. The parameters of track components were identical with those of site 1 .

2.2.3. Site 3 Baotou-Shenmu Railway. Site 3 was located in the transition of Yellow River Bridge, approximately $10.8 \mathrm{~km}$ south from the Wanshuiquan station (Figure 4(c)). As the
Baotou-Shenmu heavy haul railway was an upgraded existing line, the rails were standard CHN60 rails with a mass of $60.64 \mathrm{~kg} / \mathrm{m}$ and fixed to the S-2 prestressed concrete sleepers with dimensions of $2.5 \mathrm{~m} \times 0.28 \mathrm{~m} \times 0.21 \mathrm{~m}$ and sleeper spacing of $0.54 \mathrm{~m}$ (1840 sleepers per $\mathrm{km}$ ). Compared with the newly built railway as site 1 and site 2, the ballast layer settlement of existing line had reached a steady state.

2.3. Studied Vehicles. For the purpose of equally comparing the vibration characteristics of these three test sites, the results of the tested trains with $\mathrm{C}_{80 \mathrm{~B}}$ wagon were analyzed in detail and the layout and geometrical specification of trains are shown in Figure 5. $\mathrm{DF}_{4 \mathrm{~B}}$ diesel locomotive is supported by two bogies (each with three axles) with the length $L_{v}$ of $20.5 \mathrm{~m}$, interbogie interval $L_{b}$ of $12 \mathrm{~m}$, and axle spacing $L_{a}$ of $1.8 \mathrm{~m} . \mathrm{SS}_{4 \mathrm{~B}}$ electric locomotive is a combination consisting of two identical components, each of which is supported by four axles with $L_{v}, L_{b}$, and $L_{a}$ are $15.2 \mathrm{~m}, 8.2 \mathrm{~m}$, and $2.9 \mathrm{~m}$, respectively. $\mathrm{C}_{80 \mathrm{~B}}$ wagon is specially designed for heavy haul coal transportation with axle load of $25 \mathrm{t}$, length of $12.0 \mathrm{~m}$, and axle spacing of $1.83 \mathrm{~m}$.

\section{Results and Analysis}

During the tests, a total of six groups of acceleration time history signals from freight trains were recorded with speed ranging from $23 \mathrm{~km} / \mathrm{h}$ to $61 \mathrm{~km} / \mathrm{h}$ and the detailed information about the formations of locomotive and wagon is shown in Table 1.

3.1. Time Domain Characteristics of Train-Induced Vibration Responses. Taking site 3 as an example, Figure 6 shows the time history and corresponding running root mean square (rms) value of the sleeper velocity during the passage of train T32 at a speed of $28 \mathrm{~km} / \mathrm{h}$. The velocities were obtained by numerically integrating the acceleration signals using a highpass digital filter with cut-off frequency of $1 \mathrm{~Hz}$ to eliminate the DC component and avoid baseline drifting, and the running rms values were computed with

$$
v_{\mathrm{rms}}=\sqrt{\frac{1}{t_{0}} \int_{0}^{t_{0}} v^{2}(t) d t},
$$

where $t_{0}$ was the width of the time window; one second was used in this paper. From these figures, it can be noticed that the sleeper response due to single axle had a short 


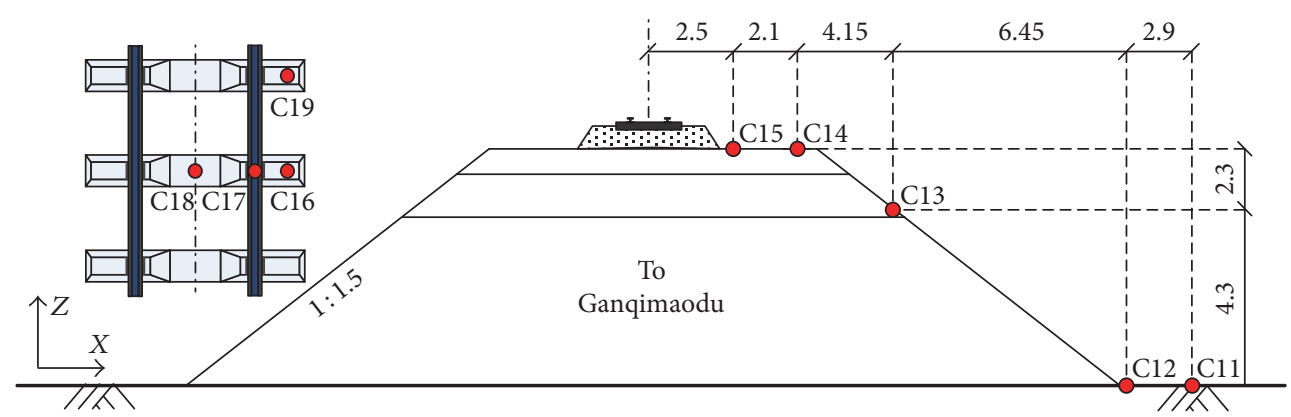

(a)

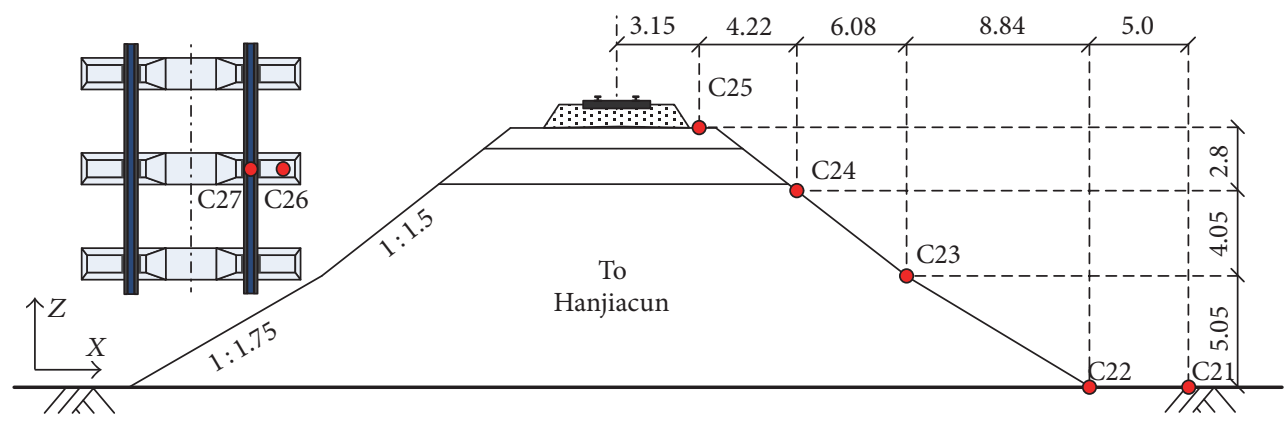

(b)

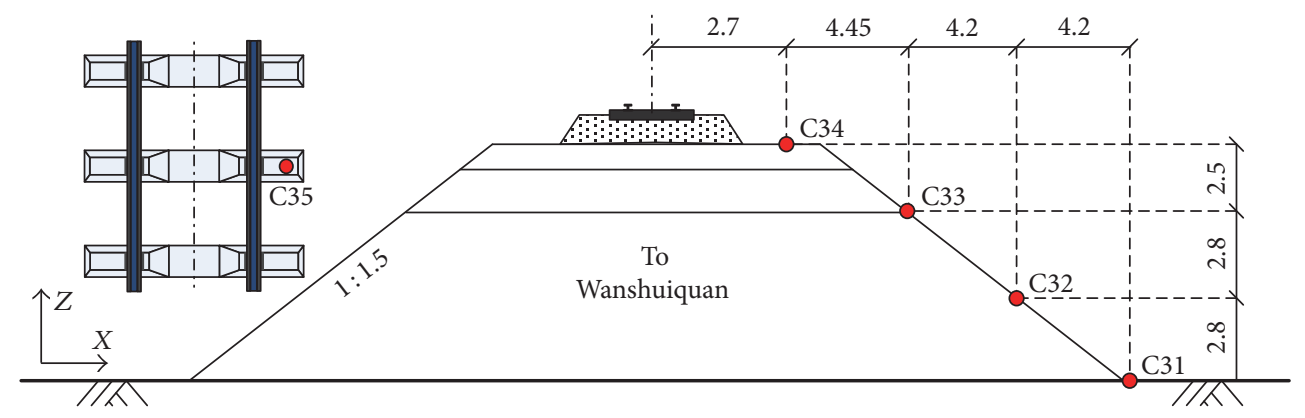

(c)

FIgURE 4: Accelerometer configuration: (a) site 1, (b) site 2, and (c) site 3.

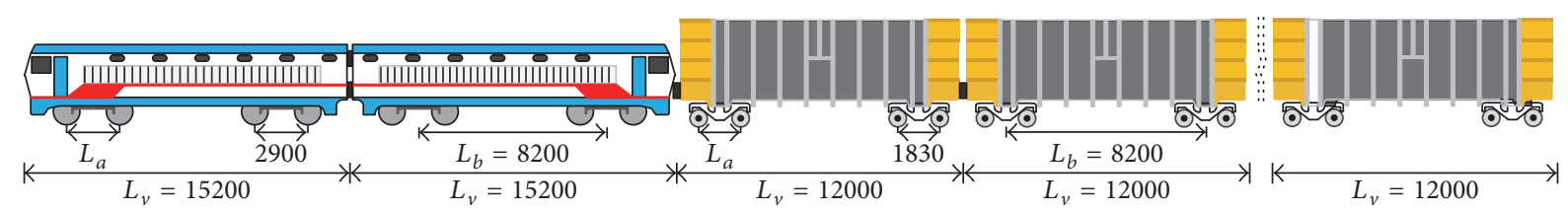

(a)

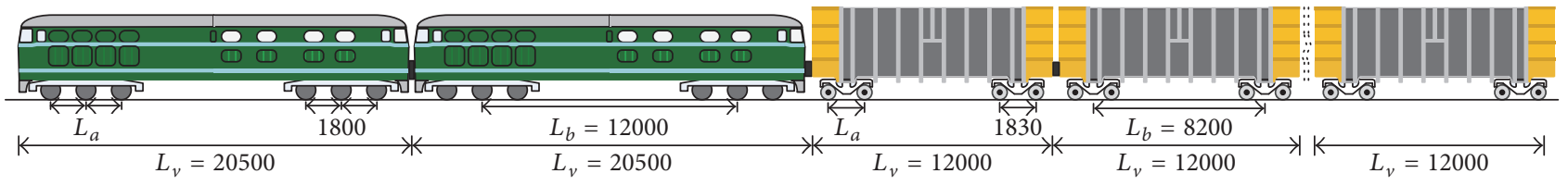

(b)

FigurE 5: The layout and geometrical specification of trains. (a) $\mathrm{SS}_{4 \mathrm{~B}}+\mathrm{C}_{80 \mathrm{~B}}$ and (b) $\mathrm{DF}_{4 \mathrm{~B}}+\mathrm{C}_{80 \mathrm{~B}}$. 


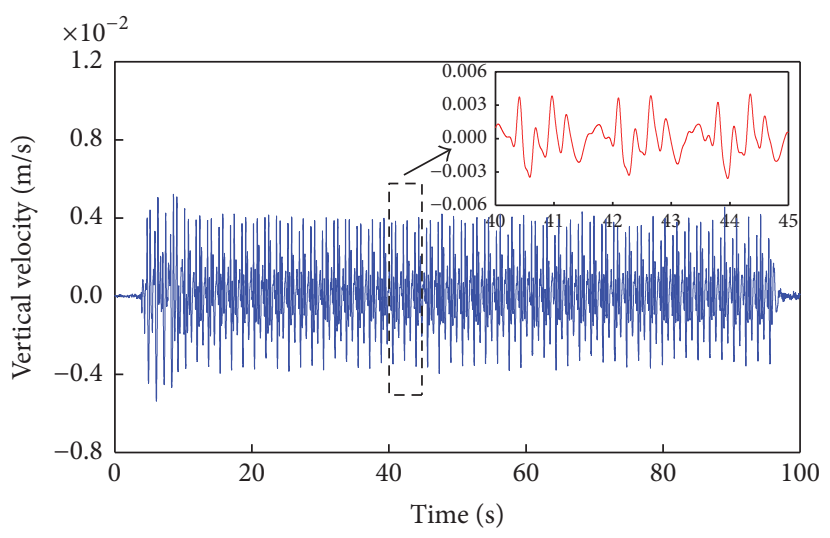

(a)

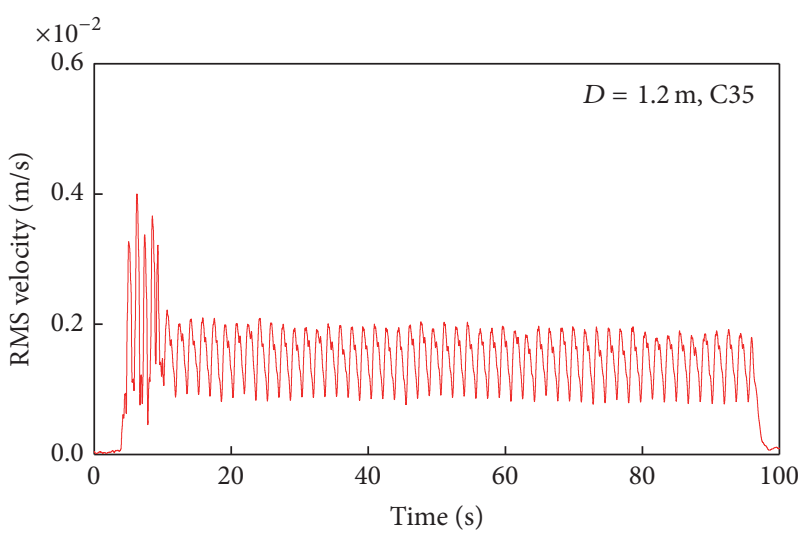

(b)

FIgURE 6: Sleeper vibration velocity due to the passage of T32 at speed of $28 \mathrm{~km} / \mathrm{h}$ : (a) time history and (b) running rms.
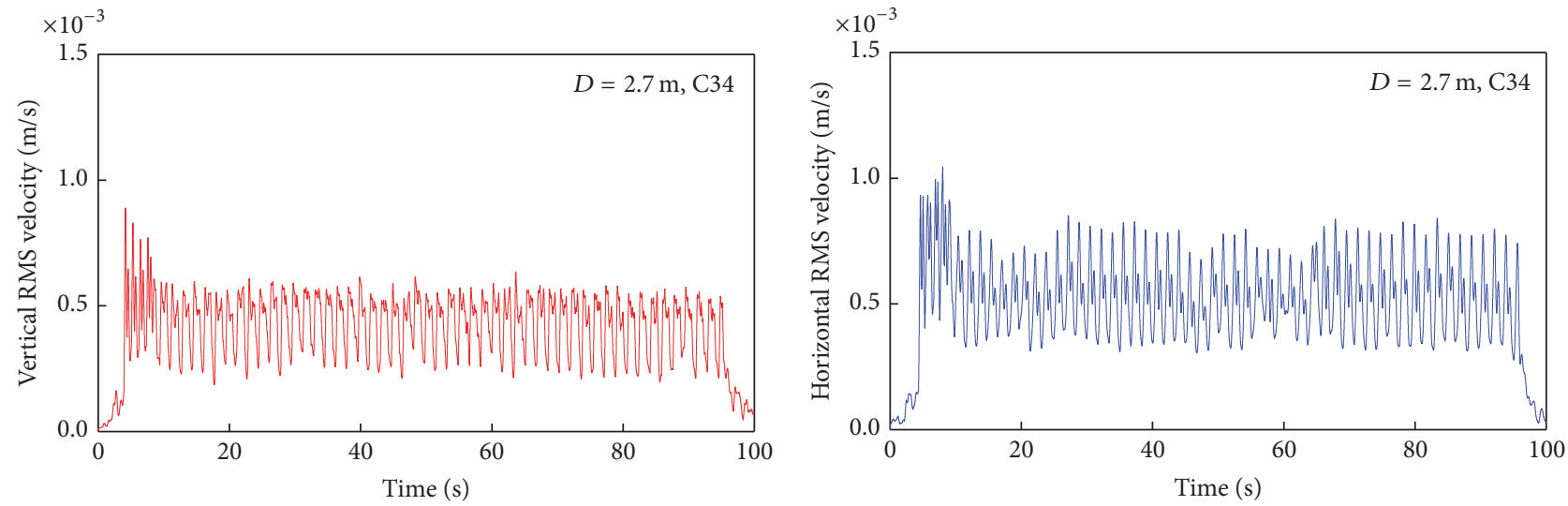

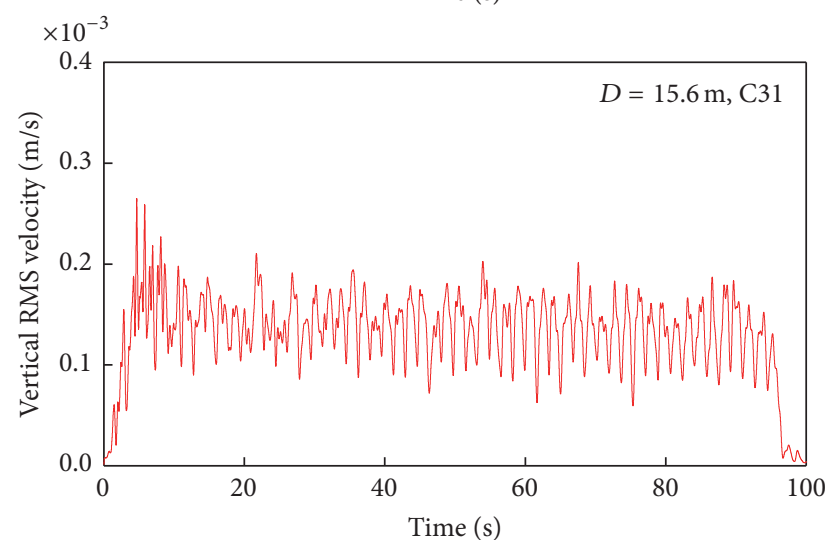

(a)

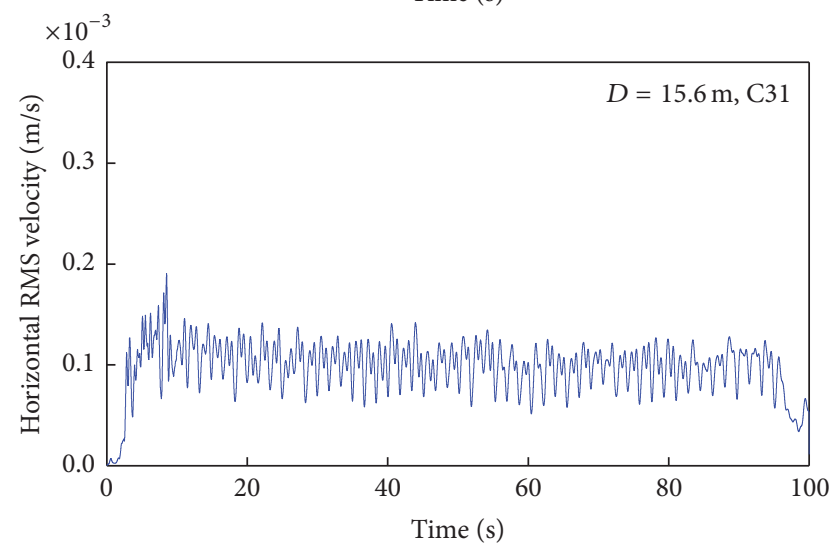

(b)

FIGURE 7: Running rms velocities of vertical (a) and horizontal (b) ground vibration at measuring points C34 and C31 due to the passage of T32 at speed of $28 \mathrm{~km} / \mathrm{h}$.

duration so that contributions of axles from different bogies did not interfere. In Figure 6(b), the running rms evolution gave a better illustration of the effects of each axle, which indicated that the quasi-static contribution dominates the sleeper response.

In the case of embankment surface vibration, Figure 7 presents a comparison of the running rms velocities in horizontal and vertical direction at $2.7 \mathrm{~m}$ and $15.5 \mathrm{~m}$ from the track center, respectively. It was found that the ground dynamic response for a single axle had a longer duration due to wave propagation in the soil, the axle contributions from different bogies tended to overlap and be undistinguishable with the increasing of distance to track center.

Compared to the results for the sleeper, lower vibration velocities for the ground surface were observed. For vertical direction, as the vibration propagated from the sleeper to 

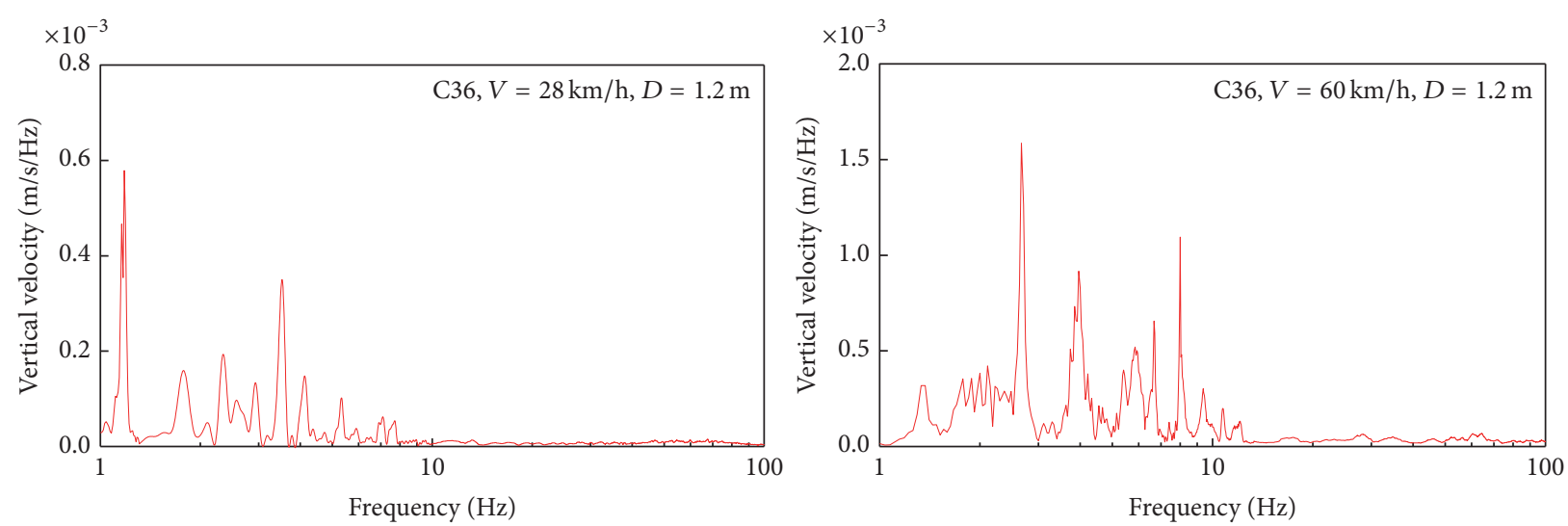

FIGURE 8: Frequency spectrum of sleeper vibration velocity with train speed of $28 \mathrm{~km} / \mathrm{h}$ and $60 \mathrm{~km} / \mathrm{h}$.

embankment top surface C34, the peak value of velocity rms dropped from $4.26 \times 10^{-3} \mathrm{~m} / \mathrm{s}$ to $0.89 \times 10^{-3} \mathrm{~m} / \mathrm{s}$, only $20 \%$ of the value at sleeper. For the farthest measuring point C31, at a distance of $18.1 \mathrm{~m}$ from track center, the peak value had declined to $0.28 \times 10^{-3} \mathrm{~m} / \mathrm{s}$. Thus it could be seen that most of the vibration energy had been dissipated during the propagation due to the geometrical damping effects and the internal damping of the subgrade material; this variation tendency was consistent with the results obtained in other related studies [20,31,32].

When considering the horizontal vibration, the vibration behavior and propagation rule were found to assist those in vertical direction. However, it was noticed that, at locations near the track, the horizontal vibration velocities were obviously dominant, especially for the points on embankment top surface. Despite this, as the distance from the track center increases, the horizontal vibration levels decreased rapidly and became comparable with or even smaller than the vertical levels. This was seemingly contradicted with the commonly accepted opinion that the vertical vibration played a dominant role during the vibration procedure, such as the results from Connolly et al. [20]. In fact, it was not difficult to find that the analogous conclusions were generally obtained based on free-field tests. In other words, the plausible explanation of this phenomenon was that the subgrade resistant in horizontal direction was reduced with the increasing of embankment height, eventually resulting in larger vibration levels. Furthermore, it did not exclude the possibility of a lateral track misalignment or vehicle hunting, which could also aggravate the horizontal vibration [33].

\subsection{Frequency Domain Characteristics of \\ Train-Induced Vibration Responses}

3.2.1. Excitation Mechanisms. In analyses of train-induced vibrations, a distinction is generally made between the quasistatic excitation and dynamic excitation [8]. The quasi-static excitation can be attributed to the static component of the axle loads, and the dynamic excitation is determined by the train, track, and subgrade interaction. For the purpose of better comparing the track and embankment surface vibration characteristics, Fast Fourier Transformation was performed on the velocity time histories and Figures 8 and 9 show how the vibration frequency content vary with increasing distance from the track center.

For the sleeper case (Figure 8), a significant contribution of the quasi-static excitation to the vibration velocity was found in the low-frequency range below $10 \mathrm{~Hz}$ when train speed was $28 \mathrm{~km} / \mathrm{h}$, and these peaks consisted with the multiples of fundamental axle passage frequencies. As the train speed increased to $60 \mathrm{~km} / \mathrm{h}$, it was found that a higher train speed shifts this spectrum to higher frequencies, indicating that these dominant frequencies were determined by the geometric parameters of the train axle distribution, which were not affected by the track irregularities. In other words, the quasi-static load dominated the sleeper vibration.

When the embankment surface vibration (Figure 9) was compared with the sleeper response, it was observed that two types of dominant frequencies can be identified from the frequency spectrum. On the one hand, the largest vibration amplitudes were found at $5.2 \mathrm{~Hz}$ and its low-order harmonic component. Since this dominant frequency range did not change with the increasing of distance to track center, it should be controlled by the quasi-static load.

On the other hand, another pronounced dominant frequency zone was also observed between 30 and $80 \mathrm{~Hz}$, which was attributed to the dynamic response caused by the interaction between the train and track [34]. In addition, it was found that these dominant frequencies showed a strong shift to lower sections with the increasing of the distance from track center. This can be explained as follows. Due to the material damping in the soil, the high frequency vibrations generated by the track irregularities were damped rapidly as they propagate through the embankment surface [12]. In contrast, the vibrations with lower frequency can propagate to larger distances due to their longer wavelengths. Therefore, these two types of peak frequencies should be isolated to reduce the train-induced embankment vibration.

3.2.2. Comparison of Vibration Direction. Although the spectrum curve is convenient for analyzing the quasi-static vibration characteristics, there is no need to consider all 

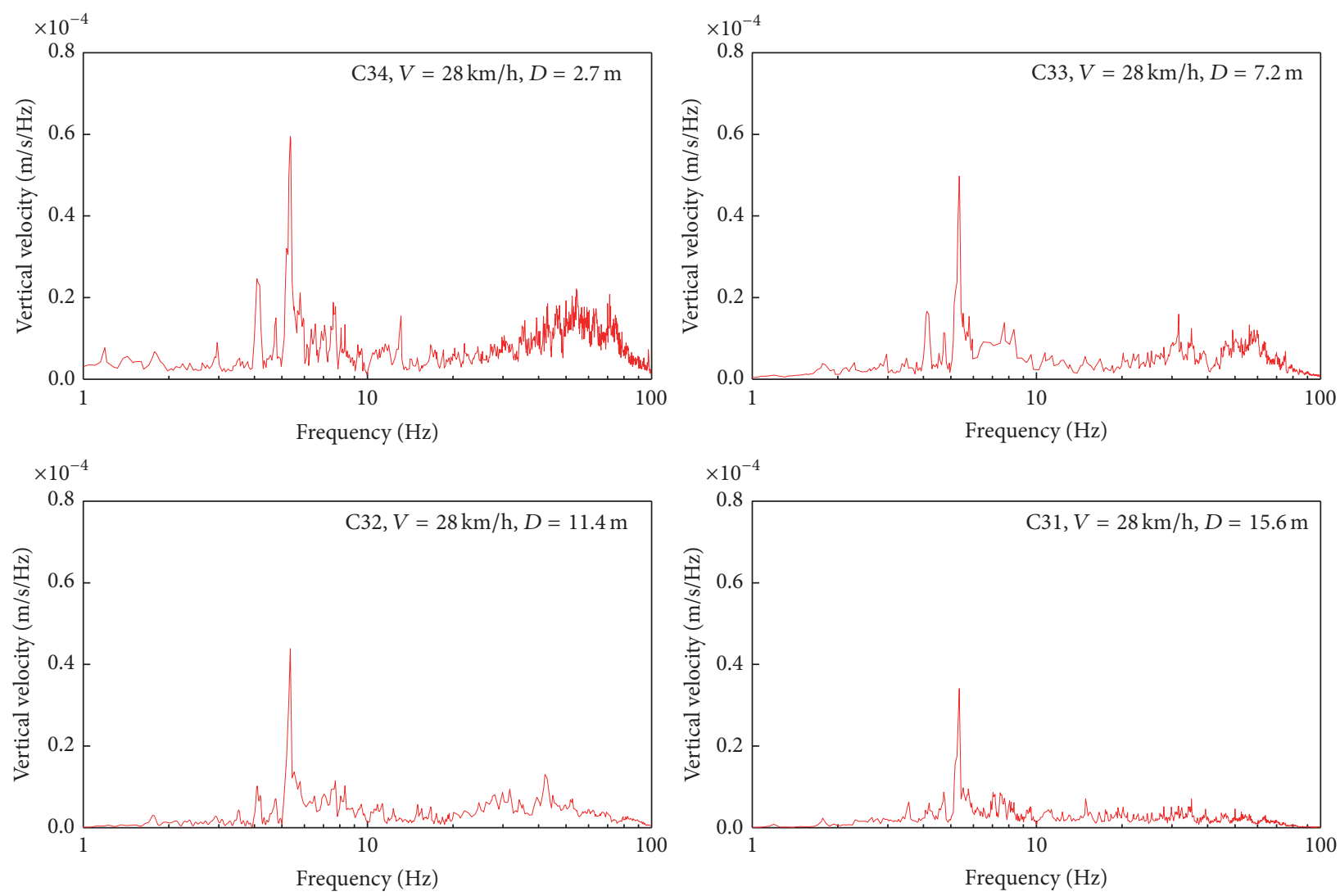

FIGURE 9: Frequency spectrum of the vertical embankment surface velocity at train speed of $28 \mathrm{~km} / \mathrm{h}$.

the frequency components in detail. Therefore, to clearly present the vibration difference between the vertical and horizontal direction, the one-third octave bank spectra of the vibration velocity were calculated, as shown in Figure 10. The vertical axis represented the velocity amplitude, denoted by the vibration velocity level (VL) with unit $\mathrm{dB}$.

$$
\mathrm{VL}=20 \log _{10}\left(\frac{v_{\mathrm{rms}}}{v_{0}}\right),
$$

where $v_{\text {rms }}$ was the root mean square of the vertical vibration velocity and $v_{0}$ was the reference vibration velocity with value of $1.0 \times 10^{-8} \mathrm{~m} / \mathrm{s}$.

We can see that the major difference was reflected in the two dominant frequency ranges mentioned above. Compared with the embankment vertical vibration response, there were no obvious peaks in the first dominant frequency range for horizontal vibration, suggesting that the quasistatic excitation contributed more to the vertical vibration. For the measuring points on embankment top surface and side slope, the horizontal vibration was more prominent in the second dominant frequency range; thus it can be seen that the dynamic excitation took a more important role on the horizontal vibration for this embankment section. As the vibration propagated to $\mathrm{C} 31$, the influences of dynamic excitation in both directions had been greatly reduced and then the vibration was mainly induced by quasi-static load.
3.3. Factors Affecting Embankment Vibration. Factors affecting the embankment vibration can be classified as trainrelated (train type and speed) and track-related (track bed thickness, subgrade top surface stiffness, etc.). According to the data measured in this experiment, the effects of train type and speed on the embankment vibration will be analyzed below. In view of the significant difference in structure and static weight distribution, the values induced by locomotives and wagons were calculated separately.

3.3.1. Train Type. Without considering the mechanism behind vibration propagation during passage of trains, Figure 11 shows the measured peak particle velocities (PPV) induced by locomotive and wagon at different distance from track center. The PPV is calculated as

$$
\mathrm{PPV}=\max |v(t)|,
$$

where $v(t)$ was the running rms velocity time history.

As can be seen, the velocity amplitudes generated by locomotive were found to be evidently greater than those from the rear wagons for all these three test sites. This phenomenon had been observed in most of the field tests $[17,35]$, and the reason was mainly attributed to larger axle weight or the superimposed effect among axles. Based on the data from different train formations in this test, however, it was not the key for vibration differences. For one thing, considering the static weight of train, the axle load of $\mathrm{DF}_{4 \mathrm{~B}}$ 

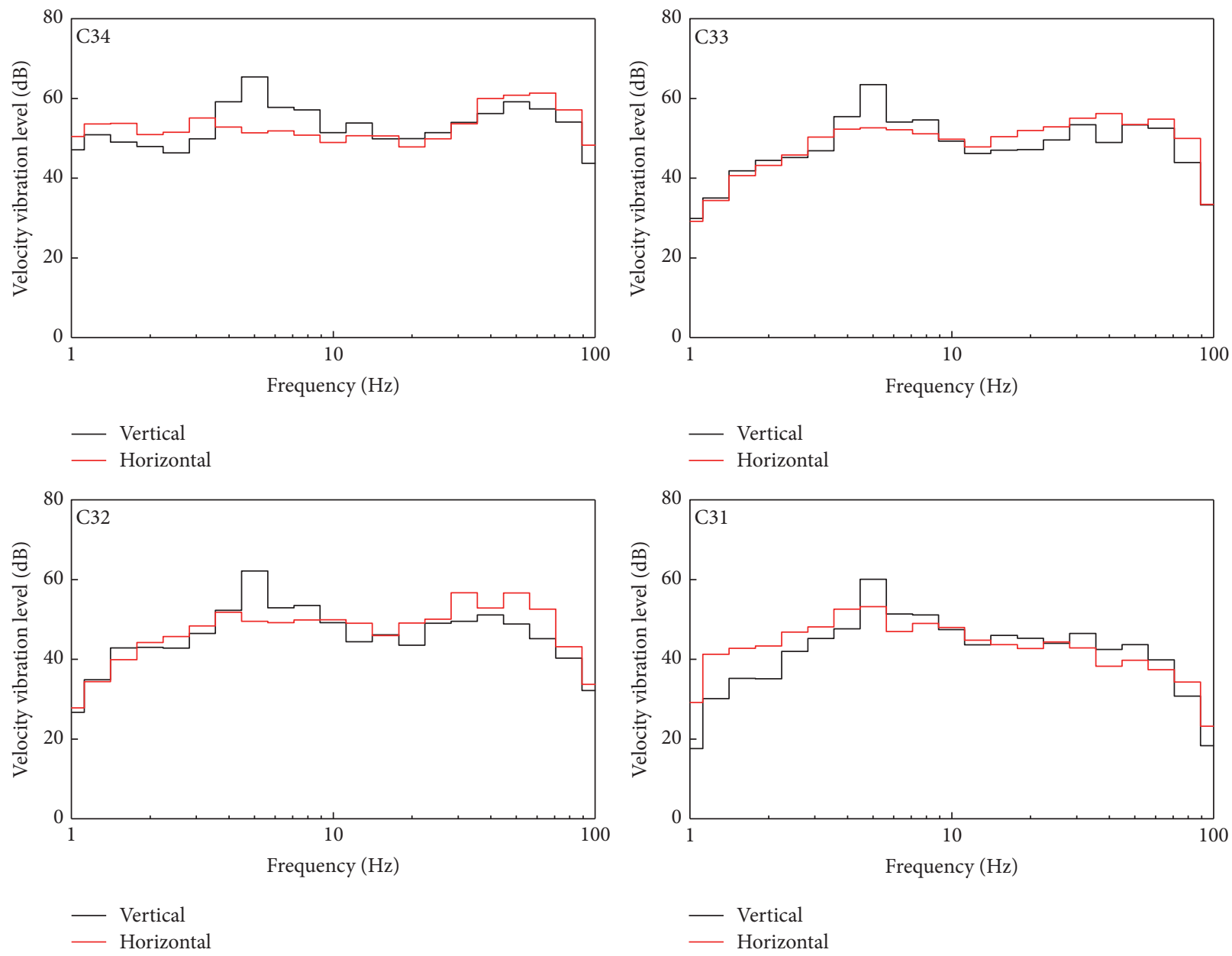

FIGURE 10: One-third octave band spectra of the embankment surface vibration velocity in vertical and horizontal direction.

locomotive was $23 \mathrm{t}$, a little lower than that of wagon $\mathrm{C}_{80 \mathrm{~B}}$. In addition, the axle arrangement configuration of SS4B was also the same as that of wagons.

In view of this, the author attributed the primary cause to the different bogie suspension mode. Compared with wagon bogie, the primary suspension in locomotive restrained the influence of wheel-rail impact force on the bogie, resulting in higher vibration of the unsprung mass. Taking the subgrade top surface measuring points on site 1 and site 3 , Figure 12 shows the comparison of the vibration velocity levels induced by locomotive and wagon. As shown, in the low-frequency region, the vibration level of wagon was clearly larger than locomotive, especially for the vertical direction; this phenomenon was consistent with the fact that wagon axle load was larger than that of locomotive. By contrast, larger vibration level was observed for locomotive in frequency range between 30 and $80 \mathrm{~Hz}$, indicating the dominant effect of dynamic excitation [36].

3.3.2. Train Speed. Figure 13 presents the vibration velocity levels with different train speed on test site 3 . As expected, we can see that the increase of the dynamic load with train speed affects the embankment vibration, so that a slightly higher intensities were obtained for increasing train speed. Madshus et al. [18] had pointed out that the ground vibration will increase significantly as train speed exceeding the site Rayleigh wave velocity. Despite it was difficult for the designed speed of heavy haul railway to reach this critical value, according to the measured data during this field test, obviously the effect of train speed on the subgrade vibration should not be ignored.

\subsubsection{Attenuation of Vibration with Distance from Track Cen-} ter. In order to compare the vibration attenuation rules of these three test sites, Figure 14 illustrates the variation of peak particle velocity with the distance from track center, where the PPV was normalized by dividing the corresponding values at all distances by the one measured at the nearest point to free the data from the influences of train type and speed.

As can be seen, these figures showed an approximately exponential function relationship between the normalized PPV and distance from the track center in doubly logarithmic scales, especially for the vibration in vertical direction. This 

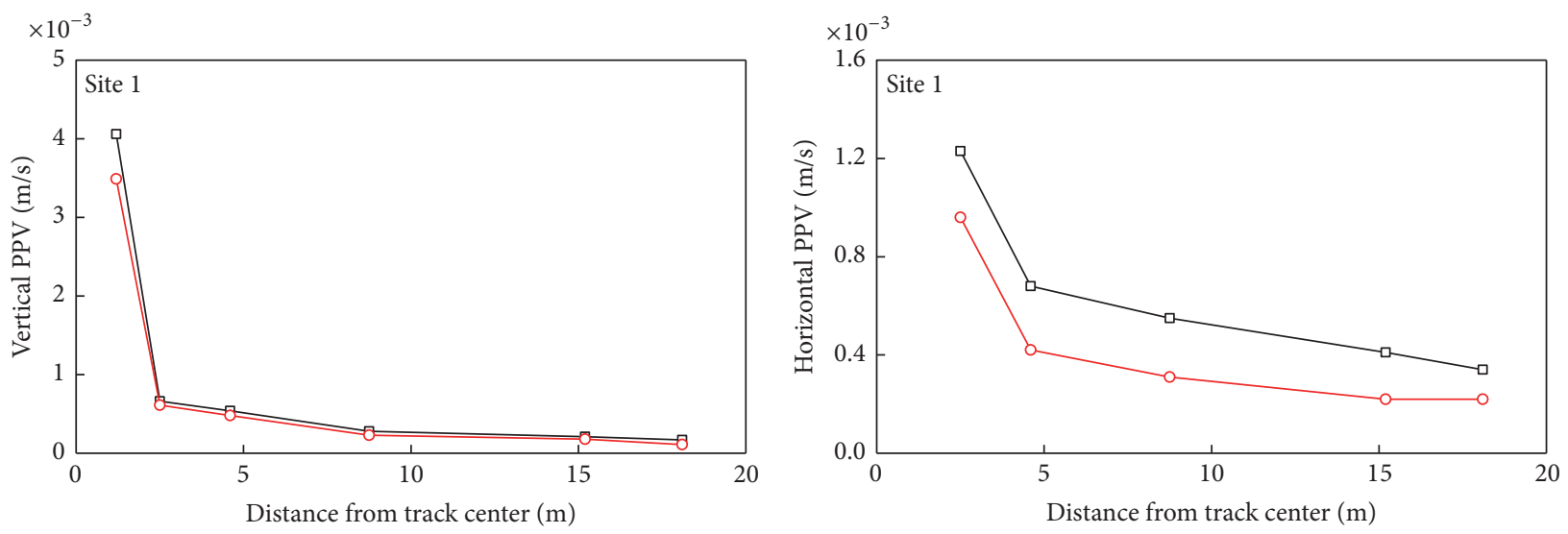

$\rightarrow \square$ Locomotive, $\mathrm{DF}_{4 \mathrm{~B}}$
$\rightarrow-$ Wagon, $\mathrm{C}_{80 \mathrm{~B}}$

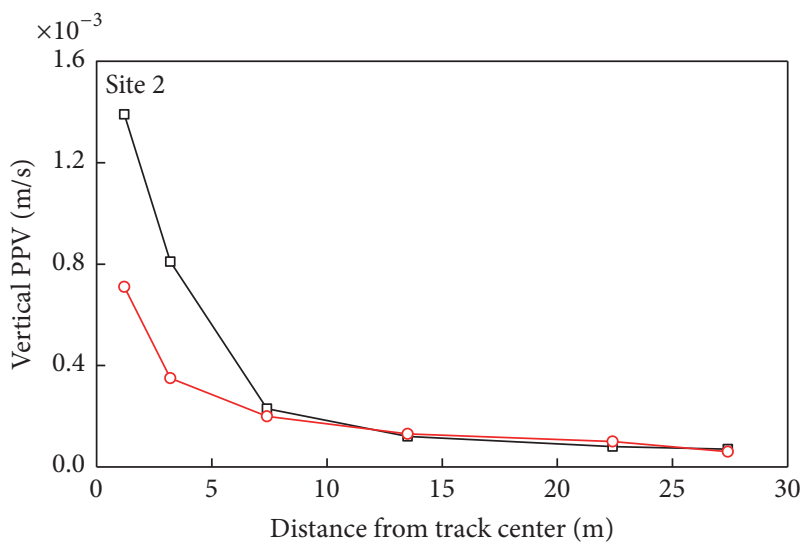

$\neg-$ Locomotive, $\mathrm{DF}_{4 \mathrm{~B}}$

$\multimap$ Wagon, $\mathrm{C}_{80 \mathrm{~B}}$

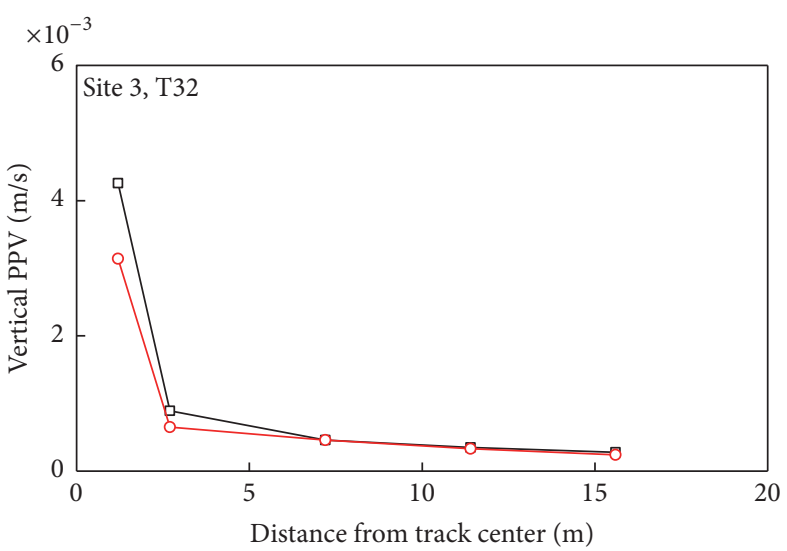

$\rightarrow-$ Locomotive, $\mathrm{SS}_{4 \mathrm{~B}}$

- Wagon, $\mathrm{C}_{80 \mathrm{~B}}$ $\square-$ Locomotive, $\mathrm{DF}_{4 \mathrm{~B}}$

$\multimap$ Wagon, $\mathrm{C}_{80 \mathrm{~B}}$

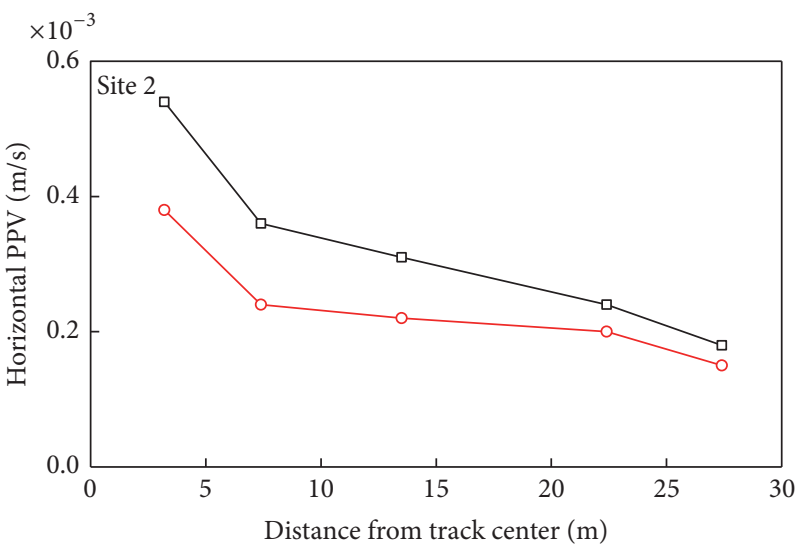

$\neg-$ Locomotive, $\mathrm{DF}_{4 \mathrm{~B}}$

- - Wagon, $\mathrm{C}_{80 \mathrm{~B}}$

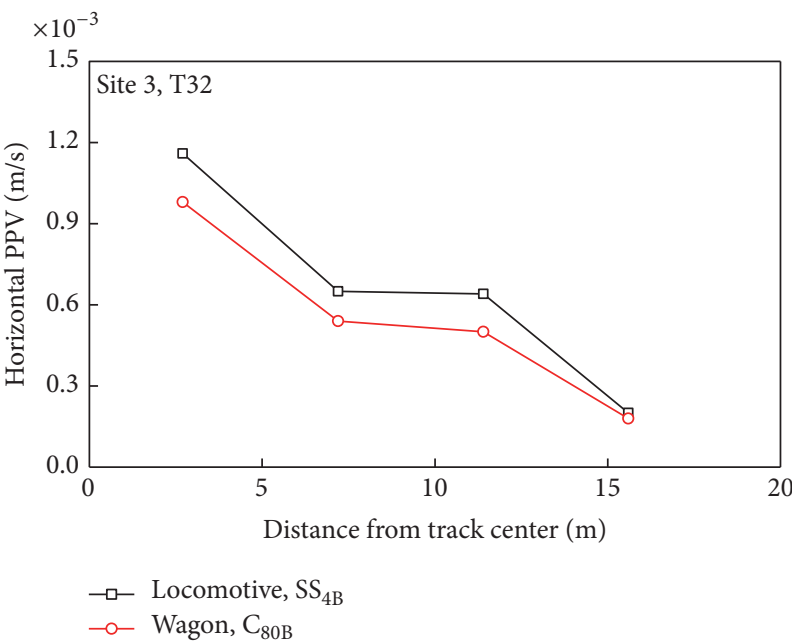

FIGURE 11: Comparison of PPV induced by locomotive and wagon.

general attenuation rule was similar to the results reported by Ling et al. [31] based on Qinghai-Tibet railway site. Here the relationship was expressed as the following equation:

$$
\log A=m \cdot(\log r)^{p}
$$

where $A$ was the normalized PPV, $r$ was the distance from the track center, and $m$ and $p$ were site parameters. The obtained site parameters are presented in Table 2 . It was found that the slope of the curve $m$ increases with the increasing of embankment height, suggesting that the increase of embankment height restrained the vibration level reduction rates. In 

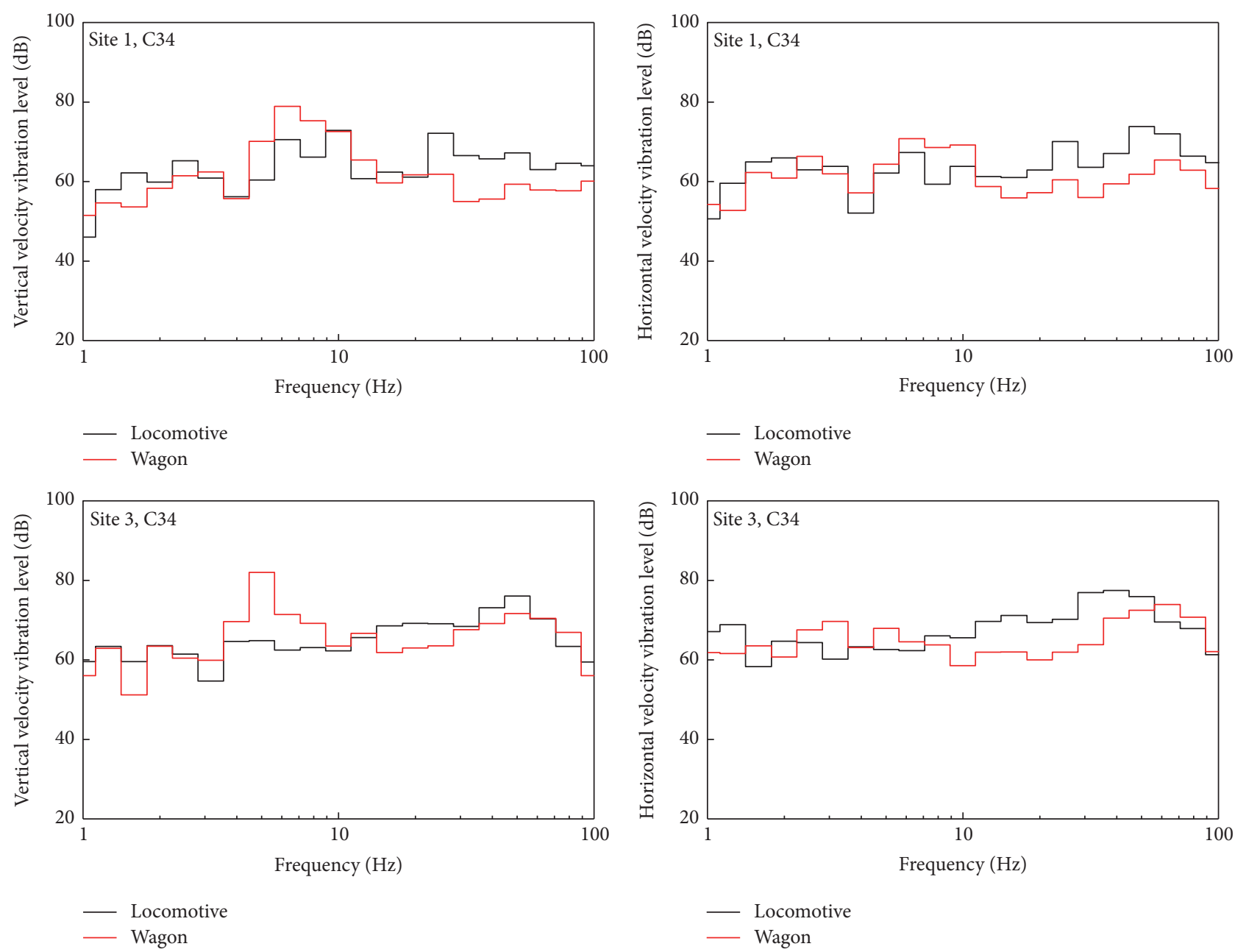

FIGURE 12: Comparison of the one-third octave band spectra induced by locomotive and wagon.

TABLE 2: Site attenuation parameter.

\begin{tabular}{lcccccc}
\hline Site & \multirow{2}{*}{ Height } & \multicolumn{3}{c}{ Vertical direction } & \multicolumn{3}{c}{ Horizontal direction } \\
& & $m$ & $p$ & $R^{2}$ & $m$ & $R^{2}$ \\
\hline Site 1 & $6.6 \mathrm{~m}$ & -1.22 & 0.709 & 0.948 & -0.437 & 0.868 \\
Site 3 & $8.1 \mathrm{~m}$ & -1.083 & 0.758 & 0.918 & -0.296 & 4.771 \\
Site 2 & $11.9 \mathrm{~m}$ & -0.745 & 1.265 & 0.915 & -0.189 & 2.136 \\
\hline
\end{tabular}

particular, to the case of horizontal direction, some vibration amplitudes of C32 were observed larger than those of C33, especially for the locomotive components. This phenomenon was consistent with the numerical results of Gao et al. [37]. It was postulated that the amplitude rebound was generated due to the lateral vibration waves reflecting from the edges of the embankment surface.

\section{Conclusions}

Field experiments were carried out at three heavy haul railway sites with increasing height for the purpose of investigating the characteristics and propagation rules of traininduced ground vibration. During the tests, the vibration acceleration histories of the rail, sleeper, and embankment surface were recorded, and then the propagation characteristics of ground vibration were contrastively analyzed in both time and frequency domain.

Analysis of the measured results revealed the following.

(1) Contrary to commonly accepted theory, at locations near the track, horizontal vibration levels were dominant for embankment surface. But as the distance from track center increases, the vibration in horizontal direction decreased rapidly and became comparable with or even smaller than the vertical levels.

(2) The quasi-static excitation dominated the sleeper response, and the dominant frequency range was found in the low-frequency zone corresponding to the fundamental 

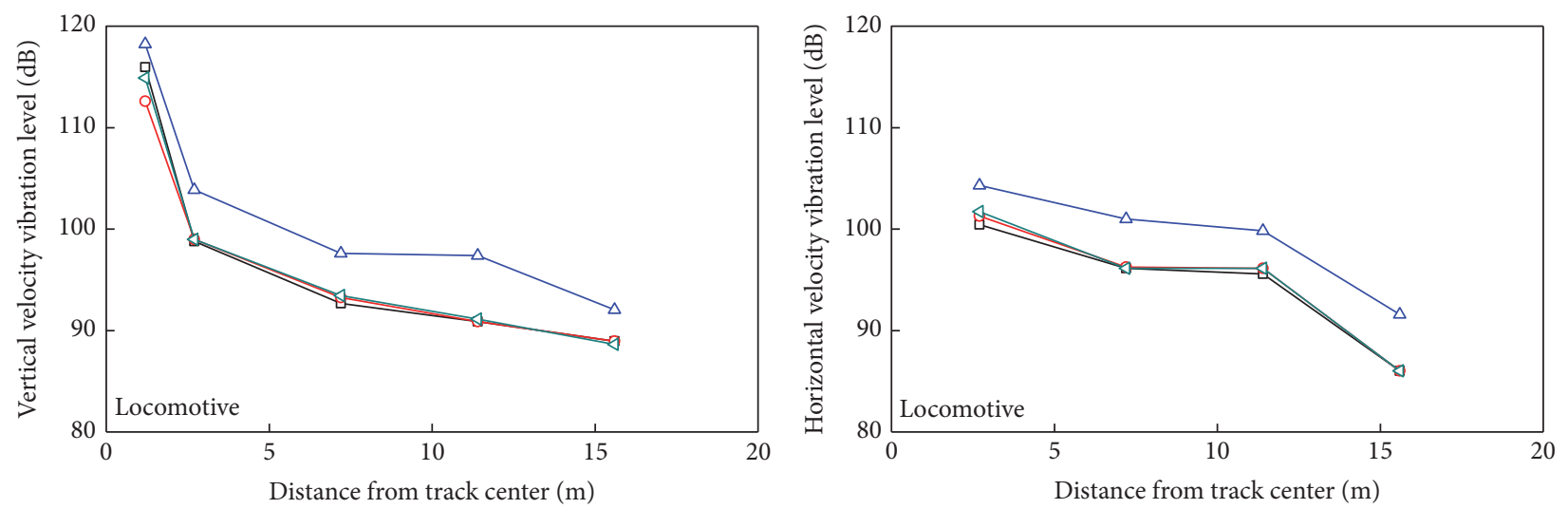
$\neg-26 \mathrm{~km} / \mathrm{h}$
$\triangle-60 \mathrm{~km} / \mathrm{h}$
$\multimap-28 \mathrm{~km} / \mathrm{h}$
$\smile 25 \mathrm{~km} / \mathrm{h}$
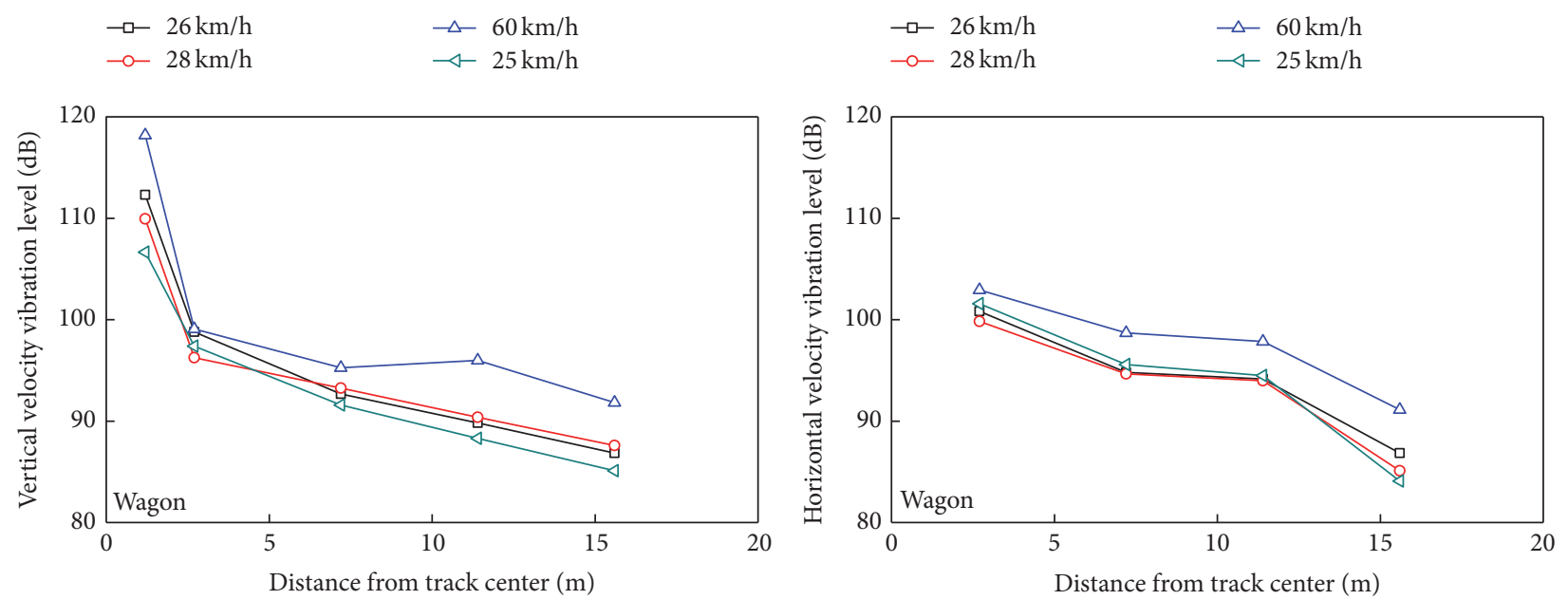

$\rightarrow-26 \mathrm{~km} / \mathrm{h}$

$\triangle 60 \mathrm{~km} / \mathrm{h}$

$\rightarrow-26 \mathrm{~km} / \mathrm{h}$

$\triangle-60 \mathrm{~km} / \mathrm{h}$

$-0-28 \mathrm{~km} / \mathrm{h}$

$\neg-25 \mathrm{~km} / \mathrm{h}$

$\multimap-28 \mathrm{~km} / \mathrm{h}$

$\triangleleft-25 \mathrm{~km} / \mathrm{h}$

FIGURE 13: Comparison of vibration velocity level with various running speeds.
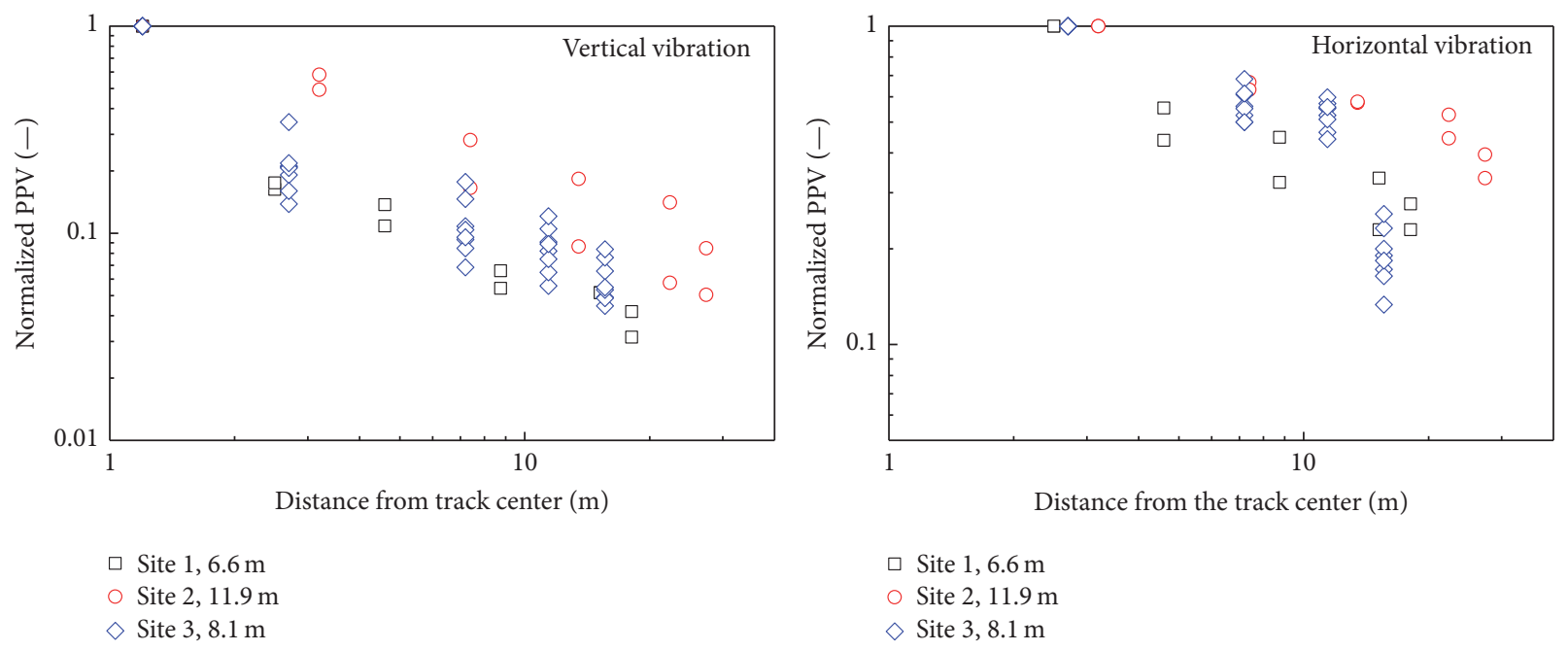

ite $1,6.6 \mathrm{~m}$

$\diamond$ Site $3,8.1 \mathrm{~m}$

FIGURE 14: Normalized PPV attenuation rule with distance from track center in vertical and horizontal direction. 
axle passage frequency as well as its low-order harmonic component. For embankment surface vibration, another pronounced dominant frequency zone was also observed between 30 and $80 \mathrm{~Hz}$, which was attributed to the dynamic response caused by the interaction between the train and track. In addition, the higher frequency components were more promptly attenuated than low-frequency ones, so the dominant frequency range of embankment tended to move towards lower section with the increasing of the distance to track center.

(3) Vibrations in vertical and horizontal direction were induced by different excitation mechanisms. The quasi-static excitation contributed more to the vertical vibration, and the dynamic excitation took a more important role on the horizontal vibration for the embankment section.

(4) In view of the static weight and axle arrangement configuration, the primary reason that vibration levels generated by locomotive were greater than wagon was attributed to the different bogie suspension mode. Compared to wagon bogie, the primary suspension in locomotive restrained the influence of wheel-rail impact force on the bogie, resulting in higher vibration of the unsprung mass. In addition, it did not exclude the effect of additional vibration from the locomotive engines.

(5) The relationship between normalized PPV and distance from track center in doubly logarithmic scales can be expressed with exponential function, and the vibration attenuation rates were restrained with increasing of the embankment height.

\section{Conflicts of Interest}

The authors declare that there are no conflicts of interest regarding the publication of this paper.

\section{Acknowledgments}

The authors are grateful to the Baotou-Shenmu Railway Group Company for their support during the experimental investigations. In addition, the funding provided by the National Natural Science Foundation of China (Grants nos. 51174261 and 51408163) and China Shenhua Energy Company Limited (CSIE12021243) is also greatly appreciated, without which this research work could not have been undertaken.

\section{References}

[1] P. Galvín and J. Domínguez, "Experimental and numerical analyses of vibrations induced by high-speed trains on the Córdoba-Málaga line," Soil Dynamics and Earthquake Engineering, vol. 29, no. 4, pp. 641-657, 2009.

[2] V. V. Krylov, "Effect of track properties on ground vibrations generated by high-speed trains," Acta Acustica united with Acustica, vol. 84, no. 1, pp. 78-90, 1998.

[3] G. Lombaert, G. Degrande, and D. Clouteau, "Numerical modelling of free field traffic-induced vibrations," Soil Dynamics and Earthquake Engineering, vol. 19, no. 7, pp. 473-488, 2000.
[4] C. J. C. Jones, X. Sheng, and M. Petyt, "Simulations of ground vibration from a moving harmonic load on a railway track," Journal of Sound and Vibration, vol. 231, no. 3, pp. 739-751, 2000.

[5] A. V. Metrikine, S. N. Verichev, and J. Blaauwendraad, "Stability of a two-mass oscillator moving on a beam supported by a viscoelastic half-space," International Journal of Solids and Structures, vol. 42, no. 3-4, pp. 1187-1207, 2005.

[6] X. Sheng, "Generalization of the Fourier transform-based method for calculating the response of a periodic railway track subject to a moving harmonic load," Journal of Modern Transportation, vol. 23, no. 1, pp. 12-29, 2015.

[7] R. Paolucci, A. Maffeis, L. Scandella, M. Stupazzini, and M. Vanini, "Numerical prediction of low-frequency ground vibrations induced by high-speed trains at Ledsgaard, Sweden," Soil Dynamics and Earthquake Engineering, vol. 23, no. 6, pp. 425433, 2003.

[8] G. Lombaert and G. Degrande, "Ground-borne vibration due to static and dynamic axle loads of InterCity and high-speed trains," Journal of Sound and Vibration, vol. 319, no. 3-5, pp. 1036-1066, 2009.

[9] D. Connolly, A. Giannopoulos, and M. C. Forde, "Numerical modelling of ground borne vibrations from high speed rail lines on embankments," Soil Dynamics and Earthquake Engineering, vol. 46, pp. 13-19, 2013.

[10] D. S. Kim and J. S. Lee, "Propagation and attenuation characteristics of various ground vibrations," Soil Dynamics and Earthquake Engineering, vol. 19, no. 2, pp. 115-126, 2000.

[11] G. Kouroussis, O. Verlinden, and C. Conti, "Free field vibrations caused by high-speed lines: measurement and time domain simulation," Soil Dynamics and Earthquake Engineering, vol. 31, no. 4, pp. 692-707, 2011.

[12] G. Kouroussis, D. P. Connolly, and O. Verlinden, "Railwayinduced ground vibrations-a review of vehicle effects," International Journal of Rail Transportation, vol. 2, no. 2, pp. 69-110, 2014.

[13] W. Zhai, K. Wei, X. Song, and M. Shao, "Experimental investigation into ground vibrations induced by very high speed trains on a non-ballasted track," Soil Dynamics and Earthquake Engineering, vol. 72, pp. 24-36, 2015.

[14] N. Correia dos Santos, A. Colaço, P. Alves Costa, and R. Calçada, "Experimental analysis of track-ground vibrations on a stretch of the Portuguese railway network," Soil Dynamics and Earthquake Engineering, vol. 90, pp. 358-380, 2016.

[15] P. Alves Costa, R. Calçada, and A. Silva Cardoso, "Track-ground vibrations induced by railway traffic: In-situ measurements and validation of a 2.5D FEM-BEM model," Soil Dynamics and Earthquake Engineering, vol. 32, no. 1, pp. 111-128, 2012.

[16] D. P. Connolly, P. Alves Costa, G. Kouroussis, P. Galvin, P. K. Woodward, and O. Laghrouche, "Large scale international testing of railway ground vibrations across Europe," Soil Dynamics and Earthquake Engineering, vol. 71, pp. 1-12, 2015.

[17] M. Bahrekazemi, Train-induced ground vibration and its prediction [Ph.D. Thesis], Royal Institute of Technology, 2004.

[18] C. Madshus, B. Bessason, and L. Hårvik, "Prediction model for low frequency vibration from high speed railways on soft ground," Journal of Sound and Vibration, vol. 193, no. 1, pp. 195203, 1996.

[19] L. Auersch, "Train induced ground vibrations: different amplitude-speed relations for two layered soils," Proceedings of the Institution of Mechanical Engineers, Part F: Journal of Rail and Rapid Transit, vol. 226, no. 5, pp. 469-488, 2012. 
[20] D. P. Connolly, G. Kouroussis, P. K. Woodward, P. A. Costa, O. Verlinden, and M. C. Forde, "Field testing and analysis of high speed rail vibrations," Soil Dynamics and Earthquake Engineering, vol. 67, pp. 102-118, 2014.

[21] B. Olivier, D. P. Connolly, P. Alves Costa, and G. Kouroussis, "The effect of embankment on high speed rail ground vibrations," International Journal of Rail Transportation, vol. 4, no. 4, pp. 229-246, 2016.

[22] G. Kouroussis, D. P. Connolly, B. Olivier, O. Laghrouche, and P. A. Costa, "Railway cuttings and embankments: experimental and numerical studies of ground vibration," Science of the Total Environment, vol. 557-558, pp. 110-122, 2016.

[23] C. Alves Ribeiro, R. Calçada, and R. Delgado, "Experimental assessment of the dynamic behaviour of the train-track system at a culvert transition zone," Engineering Structures, vol. 138, pp. 215-228, 2017.

[24] J. N. Varandas, P. Hölscher, and M. A. G. Silva, "Threedimensional track-ballast interaction model for the study of a culvert transition," Soil Dynamics and Earthquake Engineering, vol. 89, pp. 116-127, 2016.

[25] C. González-Nicieza, M. I. Álvarez-Fernández, A. MenéndezDíaz, A. E. Álvarez-Vigil, and F. Ariznavarreta-Fernández, "Failure analysis of concrete sleepers in heavy haul railway tracks," Engineering Failure Analysis, vol. 15, no. 1-2, pp. 90-117, 2008.

[26] Y. Cai and S. S. Huang, "Dynamic measurements, investigation and analysis of da-qin heavy-haul railway track structure," Journal of Southwest Jiaotong University, vol. 3, pp. 92-98, 1993.

[27] S. W. Xiao and C. S. Lei, "Loading characteristics and dynamic response analysis of subgrade for heavy haul railway," Journal of Railway Engineering Society, vol. 31, no. 4, pp. 52-57, 2014.

[28] J. Shi, M. P. N. Burrow, A. H. Chan, and Y. J. Wang, "Measurements and simulation of the dynamic responses of a bridgeembankment transition zone below a heavy haul railway line," Proceedings of the Institution of Mechanical Engineers, Part F: Journal of Rail and Rapid Transit, vol. 227, no. 3, pp. 254-268, 2013.

[29] S. C. Liu, G. L. Ding, and L. J. Wang, "FE analysis of longitudinal dynamic response of subgrade in bridge-subgrade transition of heavy haul railway," Journal of Civil Engineering and Architecture, vol. 4, no. 5, pp. 52-59, 2010.

[30] X.-Z. Ling, L.-N. Wang, F. Zhang, S.-J. Chen, and Z.-Y. Zhu, "Field experiment on train-induced embankment vibration responses in seasonally-frozen regions of Daqing, China," Journal of Zhejiang University: Science A, vol. 11, no. 8, pp. 596605,2010

[31] X.-Z. Ling, S.-J. Chen, Z.-Y. Zhu, F. Zhang, L.-N. Wang, and Z.-Y. Zou, "Field monitoring on the train-induced vibration response of track structure in the Beiluhe permafrost region along Qinghai-Tibet railway in China," Cold Regions Science and Technology, vol. 60, no. 1, pp. 75-83, 2010.

[32] T. Dahlberg, "Vertical dynamic train/track interaction-verifying a theoretical model by full-scale experiments," Vehicle System Dynamics, vol. 24, no. 1, pp. 45-57, 1995.

[33] H. Chebli, D. Clouteau, and L. Schmitt, "Dynamic response of high-speed ballasted railway tracks: 3D periodic model and in situ measurements," Soil Dynamics and Earthquake Engineering, vol. 28, no. 2, pp. 118-131, 2008.

[34] K. L. Knothe and S. L. Grassie, "Modelling of railway track and vehicle/track interaction at high frequencies," Vehicle System Dynamics, vol. 22, no. 3-4, pp. 209-262, 1993.
[35] H. Askarinejad, M. Dhanasekar, and C. Cole, "Assessing the effects of track input on the response of insulated rail joints using field experiments," Proceedings of the Institution of Mechanical Engineers, Part F: Journal of Rail and Rapid Transit, vol. 227, no. 2, pp. 176-187, 2013.

[36] A. Colaço, P. A. Costa, and D. P. Connolly, "The influence of train properties on railway ground vibrations," Structure and Infrastructure Engineering, vol. 12, no. 5, pp. 517-534, 2016.

[37] G. Y. Gao, Z. Y. Li, and S. J. Feng, "Eeperimental results and numerical predictions of ground vibration induced by high-speed train running on Qin-Shen railway," Rock and Soil Mechanics, vol. 28, no. 9, pp. 1817-1822, 2007. 


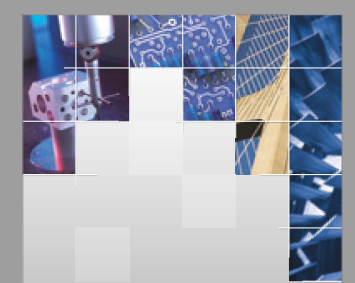

\section{Enfincering}
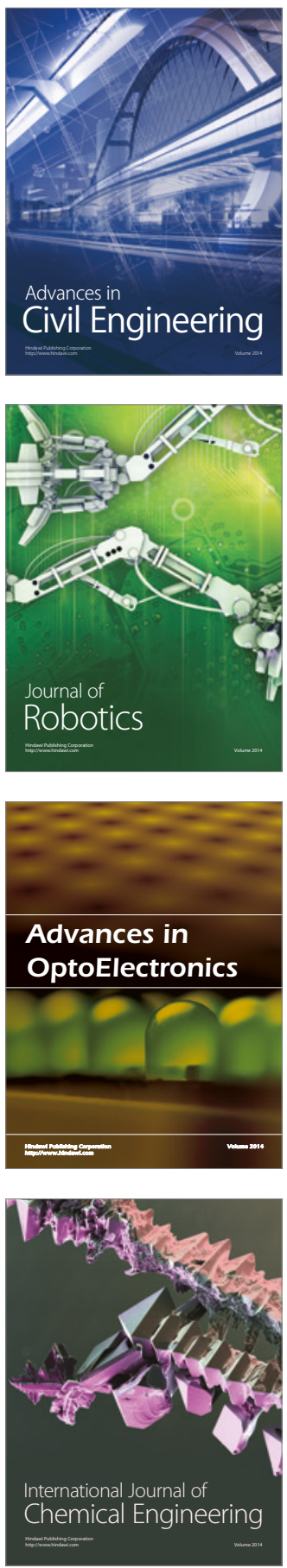

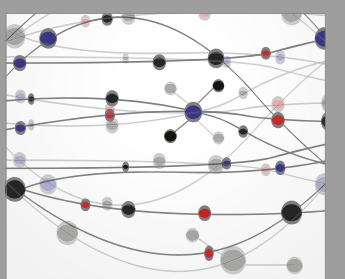

The Scientific World Journal

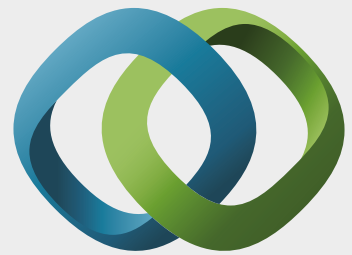

\section{Hindawi}

Submit your manuscripts at

https://www.hindawi.com
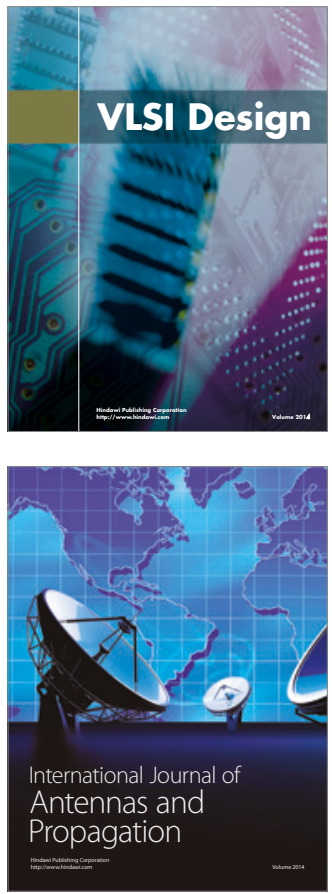

\section{Rotating}

Machinery
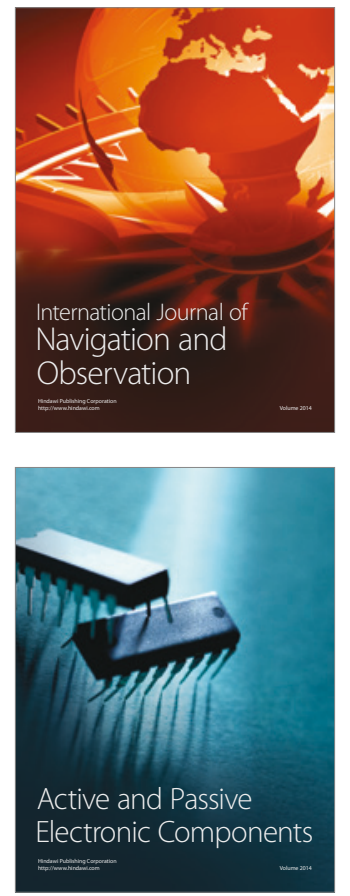
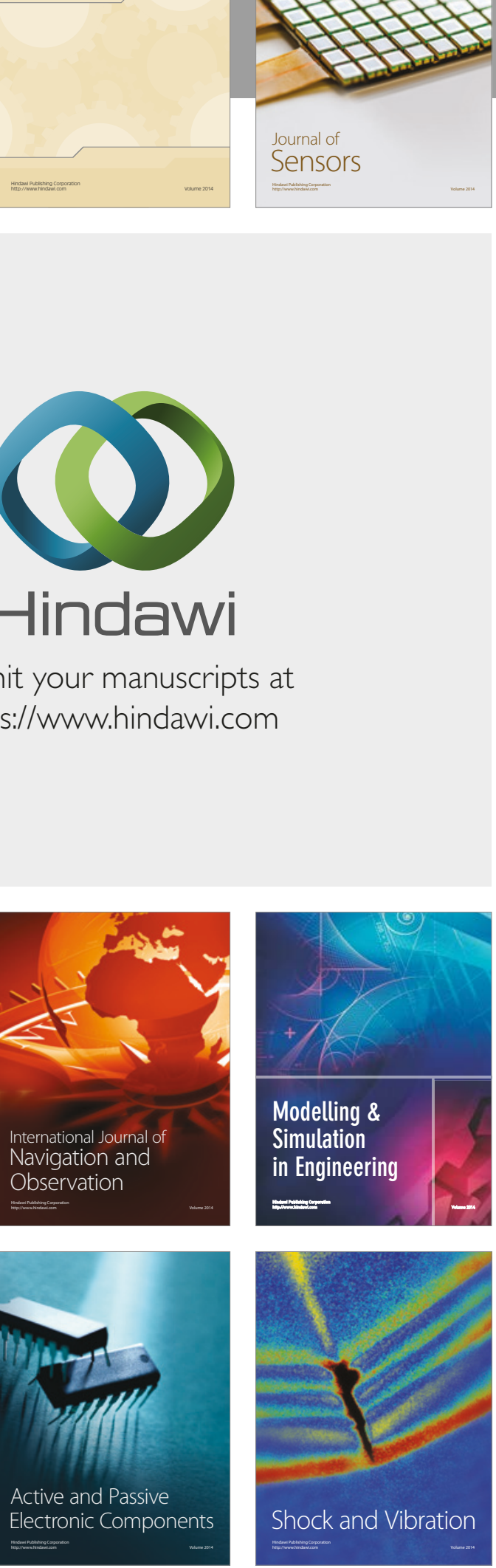
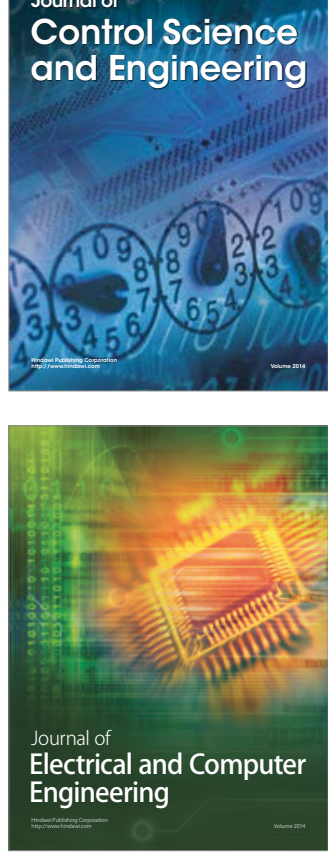

Distributed

Journal of

Control Science

and Engineering
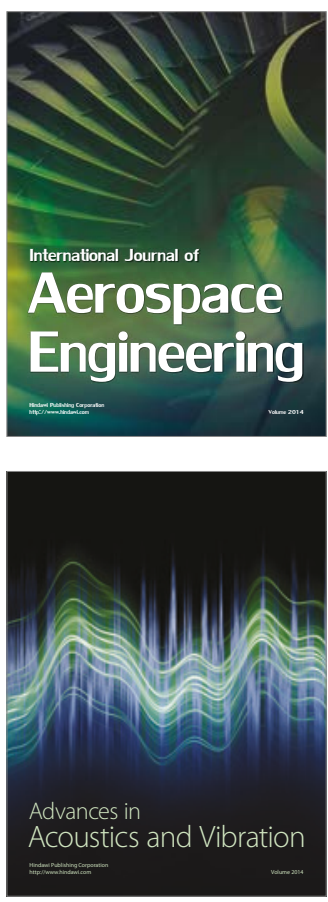

Sensor Networks 